\title{
Do anatomical contoured plates address scapula body, neck and glenoid fractures? A multi-observer consensus study
}

\author{
Japie J de Wet, ${ }^{1}$ Doopam Dey, ${ }^{1,2}$ Basil Vrettos, ${ }^{3}$ Jean-Pierre du Plessis, ${ }^{1,4}$ Cameron Anley, ${ }^{5}$ \\ Pududu A Rachuene, ${ }^{6}$ Leanne C Haworth, ${ }^{2}$ Habtamu M Yimam, ${ }^{2}$ Sudesh Sivarasu, ${ }^{2}$ Stephen JL Roche ${ }^{3 *}$ (D) \\ 1 Division of Orthopaedic Surgery, Faculty of Health Sciences, University of Cape Town, Cape Town, South Africa \\ 2 Division of Biomedical Engineering, Department of Human Biology, Faculty of Health Sciences, University of Cape Town, Cape Town, South Africa \\ ${ }^{3}$ Shoulder and Elbow Unit, Groote Schuur Hospital, University of Cape Town, Cape Town, South Africa \\ ${ }^{4}$ Orthopaedic Research Unit \\ 5 Shoulder and Elbow Unit, Tygerberg Hospital, Division of Orthopaedics, Stellenbosch University, Stellenbosch, South Africa \\ ${ }^{6} \mathrm{Dr}$ George Mukhari Academic Hospital, Sefako Makgatho Health Sciences University, Pretoria, South Africa
}

*Corresponding author: stephen.roche@uct.ac.za

Citation: De Wet JJ, Dey R, Vrettos B, Du Plessis JP, Anley C, Rachuene PA, Haworth LC, Yimam HM, Sivarasu S, Roche SJL. Do anatomical contoured plates address scapula body, neck and glenoid fractures? A multi-observer consensus study. SA Orthop J 2021;20(4):213-218. http://dx.doi.org/10.17159/23098309/2021/v20n4a4

Editor: Dr Frans Birkholtz Walk-A-Mile Centre for Advanced Orthopaedics, Pretoria, South Africa

Received: September 2020

Accepted: January 2021

Published: November 2021

Copyright: (C) 2021 De Wet JJ. This is an open-access article distributed under the terms of the Creative Commons Attribution Licence, which permits unrestricted use, distribution and reproduction in any medium, provided the original author and source are credited.

Funding: No funding was received for this study.

Conflict of interest: The authors declare they have no conflicts of interest that are directly or indirectly related to the research.

\section{Abstract \\ Background}

The surgical management of scapula body, neck and glenoid fractures remains a challenge. This study focuses on templating an available anatomical pre-contoured plating system using three-dimensional (3D)-printed scapulae to assess the ability of these plates to address the aforementioned fractures and to determine consensus on classifying scapula body, neck and glenoid fractures.

\section{Methods}

We used a cohort of 22 3D-printed scapulae prototypes and an available anatomical precontoured plating system to determine anatomical congruency and fit. Nine investigators templated the scapulae using four pre-contoured plates, and the investigators classified the 22 scapulae using the Ideberg and AO/OTA classification systems.

\section{Results}

Eleven out of 22 fractures were found to be fixable using the plates under study. The long lateral plate addressed $83 \%$ of fractures involving the lateral border, while the glenoid plate was unable to adequately address any glenoid fractures. We observed good to excellent $(p \leq 0.001)$ interobserver reliability for three of the four plates. The interobserver reliability was moderate $(I C C=0.74)$ for the AO/OTA classification and good $(I C C=0.88)$ for the Ideberg classification.

\section{Conclusion}

We believe that the anatomical pre-contoured plating system does not address all the fracture patterns encountered in clinical practice and further development in plate design is required. There is good to moderate interobserver reliability using the Ideberg fracture classification for intra-articular fractures and the AO/OTA classification for extra-articular fractures involving the body.

\section{Level of evidence: Level 3}

Keywords: scapula fracture, open reduction and internal fixation (ORIF), South Africa, scapula plate analysis, 3D printing, fracture classification

\section{Introduction}

Isolated scapula fractures are rare, accounting for 3-5\% of upper limb fractures and $0.7 \%$ of all fractures. ${ }^{1-3}$ They commonly occur in the polytraumatised patient and are generally associated with significant trauma. Low energy scapula fragility fractures sustained after falls may be found in the geriatric population. ${ }^{4}$

The scapula plays a pivotal role in maintaining the resting position of the shoulder girdle and, together with the clavicle, provides the anchor for the upper limb to the thorax. ${ }^{3}$ The rotator cuff muscles originate from the scapula and function not only as a dynamic glenohumeral stabiliser, but also in the initiation of glenohumeral motion. Loss of motion at the glenohumeral joint is well tolerated through increased scapulothoracic movement, and displaced fractures may affect this movement. The aim of scapula fracture management should be to restore shoulder function by correcting alterations in anatomy that cannot be compensated for. ${ }^{3}$

Non-surgical management of minimally to moderately displaced scapula body and neck fractures has rendered clinically acceptable and favourable long-term outcomes. However, the displaced 
Table I: The scoring system

\begin{tabular}{ll} 
Classification & Definition \\
\hline Fit & The plate fitted around the fracture within surgical limits and there was no plate overhang observed \\
\hline No-fit & The gap between the plate and the fracture line was above acceptable surgical limits and there was plate overhang \\
\hline
\end{tabular}

and intra-articular fractures types still pose a clinical dilemma due to a lack of comparative literature and well-defined surgical indications. ${ }^{2,3,5}$ Displaced and malunited intra-articular fractures lead to glenohumeral joint incongruency and increased degeneration, resulting in early onset (accelerated) arthrosis of the glenohumeral joint. ${ }^{1-3,6,7}$ Shoulder deformity with chronic pain, and stiffness, are frequently encountered in malunited scapula fractures. ${ }^{8,9}$ Rotator cuff weakness and dysfunction with impingement have also been described. ${ }^{3,4,9}$

The surgical management of scapula fractures can be difficult and challenging. Adequate fixation options are limited not only by the osseous anatomy and anatomical variability of the scapula, but also by zones of poor bone stock and the lack of bone thickness. ${ }^{1}$ The complexity of fracture patterns, challenging surgical approaches and implant limitations may lead to hesitancy from surgeons to perform open reduction and internal fixation (ORIF). ${ }^{1,10}$ Limited implant options and pre-contoured plating systems have often led surgeons to use alternate fixation systems intended for other bones to fix scapular fractures. ${ }^{11,12}$

Historically, several classification systems were proposed, attempting to guide the surgeon in decision-making and fracture management. The most used classification system was developed by the OTA Classification Committee in 1996 and revised ten years later. ${ }^{13}$ To address the limitations of the existing classification systems, the OTA Classification Committee and the AO Classification Advisory Group (CAG) collaborated to development a new validated classification system..$^{14,15}$ Although validated and reproducible, the AO/OTA classification system does not determine surgical indications, operative approaches or implant choice. ${ }^{14}$

The primary aim of this study was to quantify anatomical congruence and fit of the only available plating system in the country and to determine its fracture fixation capability. The secondary aim of the study was to determine the interobserver reliability of scapula fracture classifications and consensus among the investigators using 3D-printed scapulae.

\section{Methods}

\section{Recruitment and enrolment}

Ethical approval was obtained from the host institute's HREC (Human Research Ethical Committee). The Philips Electronics iSite Electronic Radiology System database was used to search for all shoulder CT scans performed from 1 January 2016 to

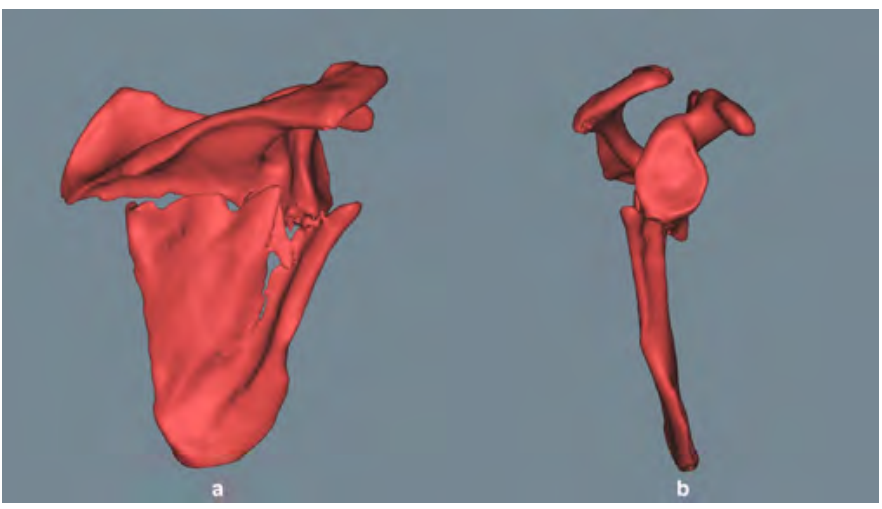

Figure 1. 3D reconstructed scapula (figure created by the authors)
31 January 2018. Twenty-six patients with closed scapula body, neck and glenoid fractures were identified.

The inclusion criterion was closed scapula body, neck and glenoid fractures. The exclusion criteria were any patient younger than 18 years, penetrating gunshot wounds, isolated acromion and/or coracoid fractures.

Twenty-two closed scapula body, neck and glenoid fractures met the inclusion criteria, while four scapula fractures were excluded as they were isolated acromion fractures. The mean age of the cohort was 46.6 years (range $26-71$ ), with a male predominance.

\section{Research procedure}

The Digital Imaging and Communication in Medicine (DICOM) files of the 22 fractures were used to create three-dimensional (3D) models (Figure 1) using Materialise Mimics ${ }^{\circledR}$ (Leuven, Belgium), and then printed using the additive manufacturing process. Each fracture fragment was anatomically reduced and glued in place to maintain the reduction. The 3D models were used to template and determine the anatomical congruency of the available pre-contoured anatomical plating system. Templating was performed with the only locally available plating system ${ }^{16}$ from Acumed $^{\circledR}$ (Hillsboro, OR, USA). The pre-contoured anatomical plating system has four plates designed to address the different anatomical locations of the scapula. The plate options were a long and a short medial plate for the medial scapula border, a long lateral plate and short lateral (glenoid) plate for the lateral border and the glenoid respectively. All four plates were templated on appropriate anatomical locations, determined by the fracture propagation through the scapula anatomy, to attain the best anatomical fixation (Figure 2).

\section{Data collection}

Nine investigators (five surgeons and four engineers) templated four plates on 22 scapulae on two separate occasions, one month apart. A scoring system, similar to our previous study, ${ }^{17}$ was applied to this study where plates were defined in an ordinal scale of fit or no-fit depending on their ability to adhere around the fractured region (Table I). Templating of the plates around fracture regions was performed in a similar way to Malhas et al. ${ }^{18}$ The scoring system considered three factors:

1.Plate overhang: defined as plate overhang on either the medial or lateral border of the scapula, preventing the placement of a screw

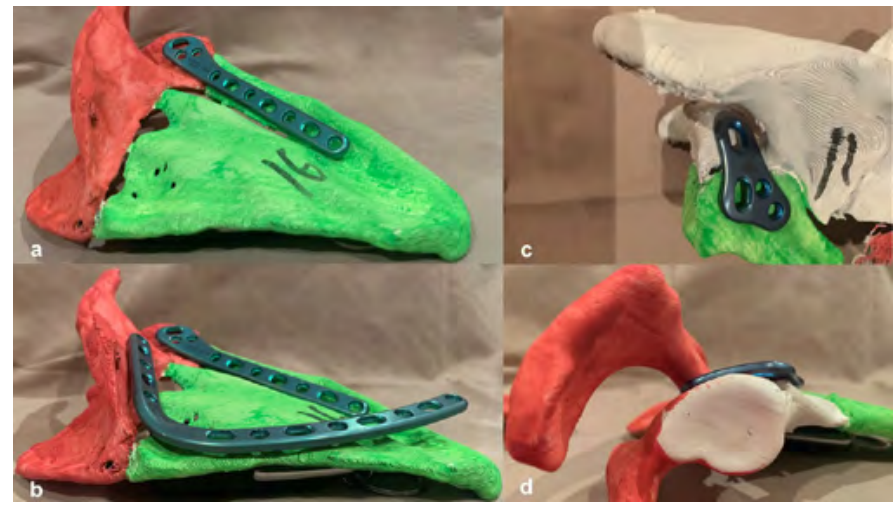

Figure 2. Templating reconstruction plates (figure created by the authors) 
2. Plate offset: defined as the distance (in millimetres) from the inferior border of the plate from the bone

3. Adequate fixation: defined as the ability of the plate to allow for placement of three screws proximal and three screws distal to the fracture line as advocated by the $\mathrm{AO}$ society fracture fixation guidelines $^{19}$

Each plate was scored and subdivided into a fit or no-fit group:

1. Fit: defined as plate offset of less than $3 \mathrm{~mm}$ with no plate overhang and adequate fixation (six cortices) proximal and distal to the fracture line

2. No-fit: defined as plate offset of more than or equal to $3 \mathrm{~mm}$ with plate overhang (as defined by the aforementioned definition) and/or inadequate fixation (less than six cortices) either proximal or distal to the fracture line

The surgeons (six) classified each scapula fracture pattern using the Ideberg classification for the glenoid fractures and the $\mathrm{AO} /$ OTA classification for the body and neck fractures. ${ }^{20,21}$ Five senior shoulder and elbow surgeons and one trainee registrar classified the fracture patterns of the 22 scapulae at a single sitting.

\section{Data analysis}

To determine the dependency of plate types and their ability to fit the fracture pattern, the chi-squared test was performed. Intraclass correlation coefficients (ICC) were calculated (model: two-way mixed; type: absolute agreement) to measure the inter-rater variability among the nine observers performing the quantitativefit analysis of the 22 scapulae. The ICC was also calculated for a fixability rating provided by the surgeons as a binary score (1: fixable; 0 : not fixable). The fracture was categorised as fixable when it was rated 1 by at least $80 \%$ of the surgeons. The classifications provided by the group of surgeons were also compared using the ICC and chi-squared tests. We reported the ICC values according to the categories specified by Koo and $\mathrm{Li}^{22}$ The cut-off for statistical significance was kept at $p<0.05$. The

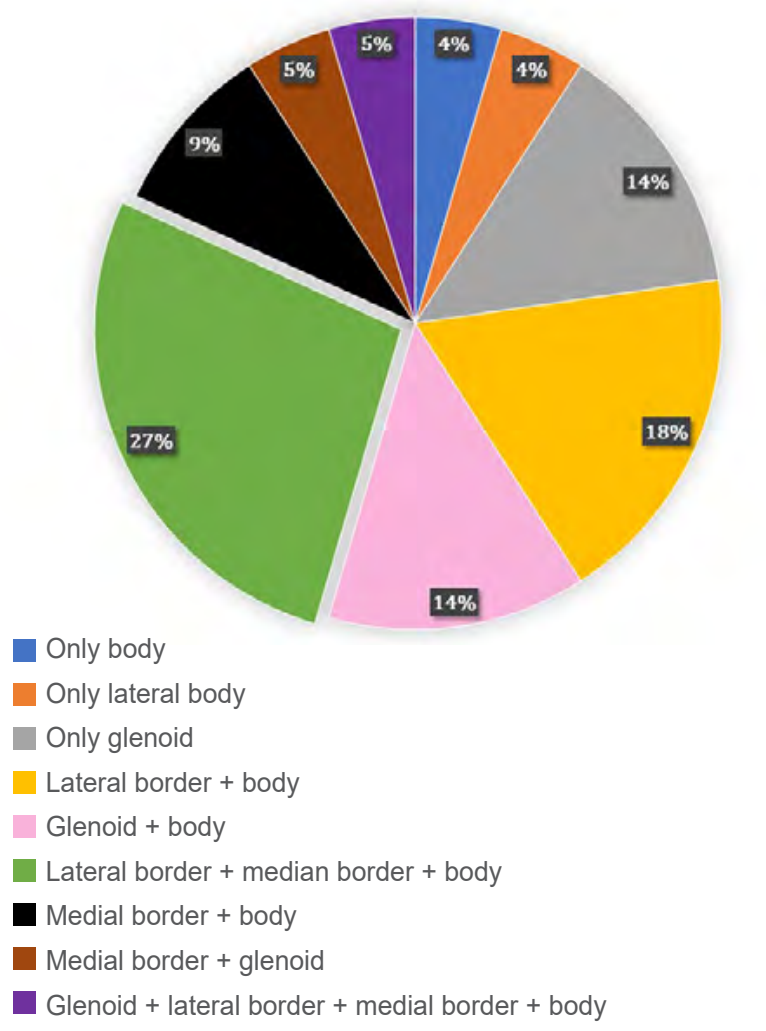

Figure 3. Fracture pattern statistical analyses were performed in IBM SPSS v.26 (IBM Co., Armonk, NY, USA).

\section{Results}

Twenty-seven per cent of fractures were found to propagate through the lateral border, scapula body and the medial border. Of the fractures, $18 \%$ involved the lateral border and the scapula body. Other fracture combinations can be seen in Figure 3. Seventy-seven per cent of the fractures involved the scapula body, $54 \%$ involved the lateral border, $45 \%$ involved the medial body, and only $36 \%$ of fractures involved the glenoid.

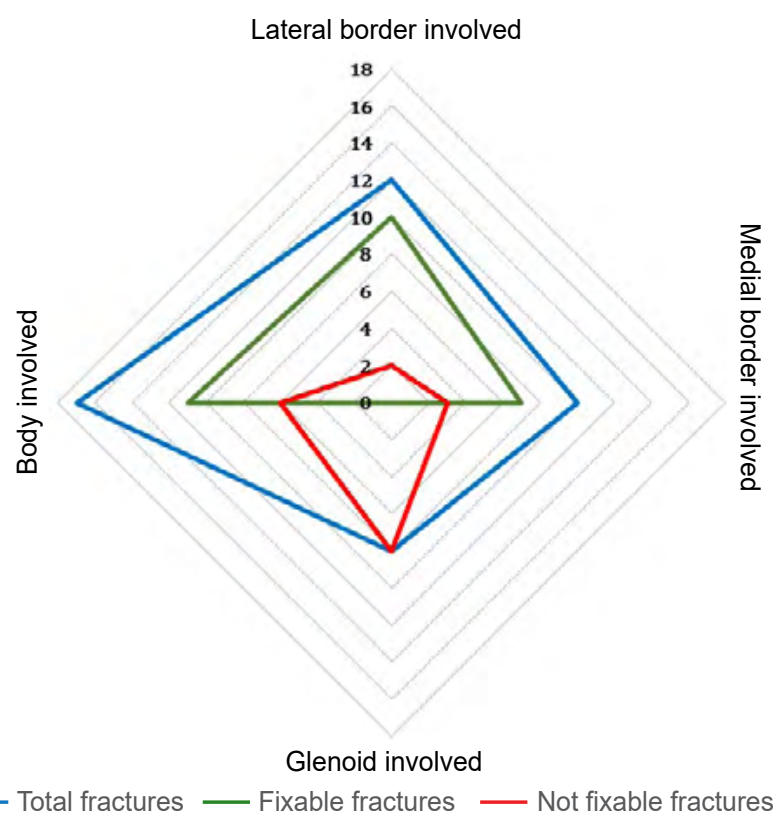

Figure 4. Flexibility potential mapped according to fracture locations

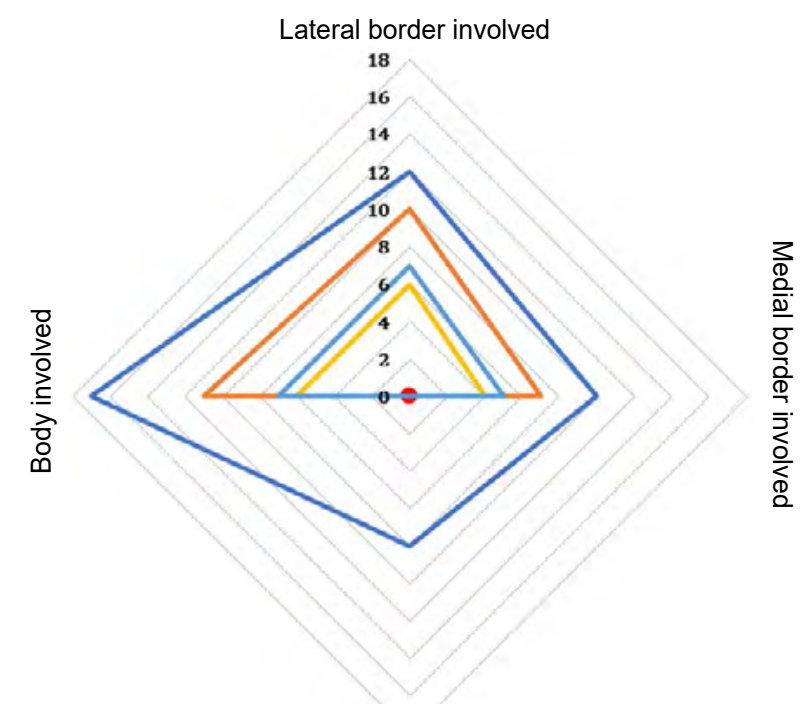

$$
\begin{aligned}
& \text { — Total fractures } \\
& \text { — Long lateral plate } \\
& \text { — Glenoid plate } \\
& \text { — Long medial plate } \\
& \text { — Short medial plate }
\end{aligned}
$$$$
\text { Glenoid involved }
$$

Figure 5. Involvement of the plates in scapula fracture fixation 
Table II: The intraclass correlation coefficient (ICC) and the corresponding $95 \%$ confidence interval (CI) calculated for the two observation sessions presented for each plate

\begin{tabular}{lcccc} 
Plates & \multicolumn{2}{c}{ First observations } & \multicolumn{2}{c}{ Second observations } \\
\cline { 2 - 5 } & ICC & $95 \% \mathrm{Cl}$ & ICC & $0.95 \% \mathrm{Cl}$ \\
Long lateral & 0.894 & $0.813-0.949$ & 0.916 & $0.952-0.960$ \\
\hline Long medial & 0.742 & $0.545-0.876$ & 0.818 & $0.678-0.913$ \\
\hline Short medial & 0.821 & $0.685-0.914$ & 0.839 & $0.697-0.917$ \\
\hline
\end{tabular}

Table III: The surgeons' observations of the scapula with isolated body fractures classified using AO/OTA classification

\begin{tabular}{|c|c|c|c|c|c|c|}
\hline & \multicolumn{6}{|c|}{ AO/OTA } \\
\hline & Surgeon 1 & Surgeon 2 & Surgeon 3 & Surgeon 4 & Surgeon 5 & Surgeon 6 \\
\hline Scapula 1 & 14B2 & 14B2 & 14B2 & 14B1P1 & 14B2 & 14B2 \\
\hline Scapula 6 & 14B1P1 & 14B1P1 & 14B1 & 14BP1 & 14B1 & 14B1 \\
\hline Scapula 7 & 14B2 & 14B2 & 14B1 & 14B1 & 14B1 & 14B1 \\
\hline Scapula 9 & 14B2P1 & 14B2 & $14 \mathrm{~A} 3$ & 14B2 & 14B2F & 14B2 \\
\hline Scapula 10 & 14B1 & 14B2 & 14B1 & 14B1 & 14B2F & 14B2 \\
\hline Scapula 12 & 14B1 & 14B2 & 14B2 & 14B2 & 14B1 & 14B1 \\
\hline Scapula 13 & 14B2 & 14B2 & 14B1 & 14B1 & 14B2 & 14B2 \\
\hline Scapula 14 & 14B1 & 14B1 & 14B2 & 14B2 & 14B2 & 14B2 \\
\hline Scapula 16 & 14B1 & 14B1 & 14B1 & 14B1 & 14B1 & 14B1 \\
\hline Scapula 20 & 14B2 & 14B2 & 14B2 & 14B2 & 14B2 & 14B2 \\
\hline Scapula 22 & 14B1 & 14B1 & 14B1 & 14B1 & 14B1 & 14B1 \\
\hline
\end{tabular}

Table IV: Surgeons' classification of isolated glenoid fractures using Ideberg classification system

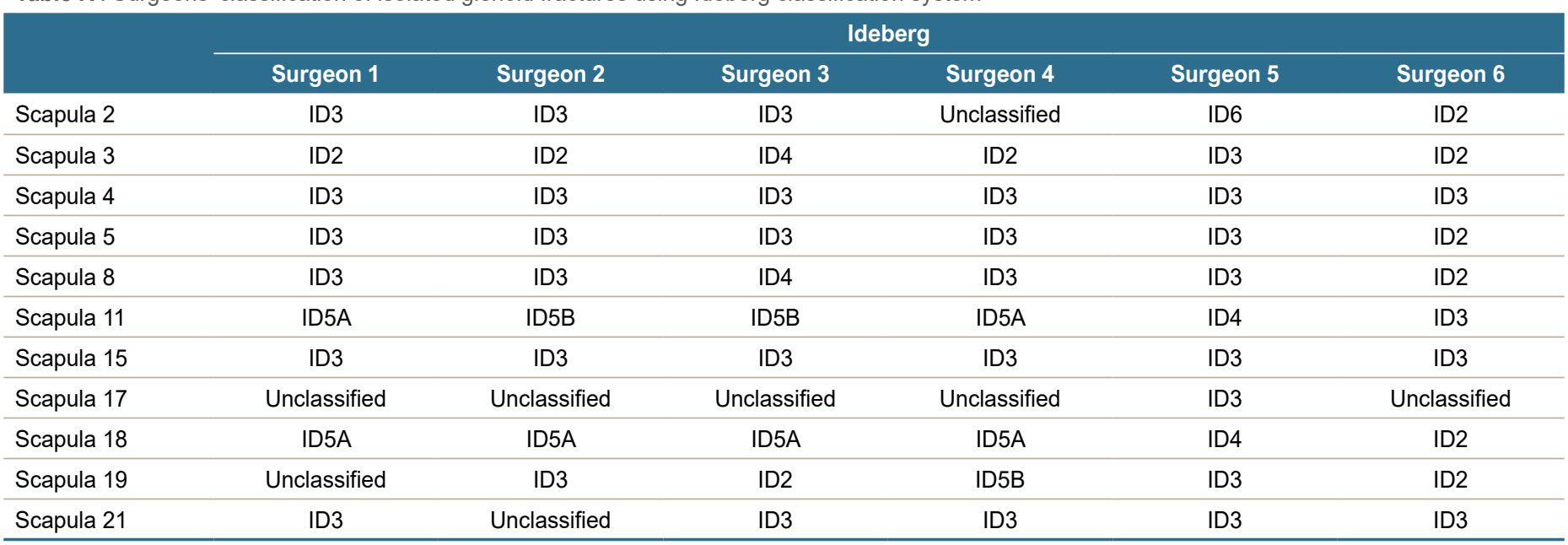

The involvement of different anatomical regions of the scapula anatomy influenced the fixability potential of the available plates $(p \leq 0.001)$. Good inter-rater reliability $(\mathrm{ICC}=0.844,95 \% \mathrm{Cl}=$ $0.712-0.927 ; p \leq 0.001$ ) was found for the fixability categorisation of the fractures. Overall, 11 out of the 22 fractured scapulae were found to be fixable using the pre-contoured plating system. None of the glenoid fractures were found to be fixable. Potential fixation could be achieved in nine (out of 17) body fractures, ten (out of 12) fractures involving the lateral border, and nine (out of 12) fractures involving the medial border (Figure 4). When a fracture was deemed fixable, a combination of a long lateral plate and at least one of the medial plates was used for six (out of 11) fractures. The rest of the fractures could be fixed using only the long lateral plate (Figure 5).

Due to the consensus that the glenoid plate was unable to fit the fracture patterns included in this study (Figure 5), we excluded the observations for the glenoid plates from the ICC calculations. For the remaining plates we observed good to excellent ( $p \leq 0.001)$ interobserver reliability (Table II).
Interobserver reliability was moderate $(\mathrm{ICC}=0.842 ; 95 \% \mathrm{Cl}=$ $0.387-0.921 ; p=0.001$ ) for the AO/OTA classification (Table III) and good $(\mathrm{ICC}=0.883 ; 95 \% \mathrm{Cl}=0.073-0.964 ; \mathrm{p} \leq 0.001)$ for the Ideberg classification (Table IV). The chi-square test suggested that the surgeon's ability to classify scapula fractures was dependent on the fracture classification being used ( $p \leq 0.001)$.

\section{Discussion}

To our knowledge this is the first study done on three-dimensional (3D)-printed scapulae and scapula fracture fixation using an anatomical contoured plating system. Nguyen et al. conducted a similar study but used computerised 3D reconstructions of scapulae and digital templating, using the same plating system. ${ }^{23}$ However, the authors used healthy cadaver scapulae, and the templating was done by digitally superimposing the plates onto the scapulae..$^{23}$ In another study, the authors physically templated anatomical plates on healthy adult museum scapula specimens. ${ }^{17}$ Despite the difference in methodologies, comparable results were 
obtained in our study and the previous ones. The results from the studies showed that the long lateral plate achieved a good fit along the fractures of the lateral border of the scapula. This can be attributed to the thicker geometry of the lateral border offering better screw purchase and the linear design pattern of the plate which makes it congruent to the anatomy of the region.

Dugarte et al. conducted a 2D versus 3D scapula fracture mapping study using computerised tomography (CT) reconstructions and found the majority of fracture lines involved the base of the spine and lateral border, just inferior to the glenoid. ${ }^{24}$ The fracture lines were least likely to involve the inferior lateral border. Armitage et al. reported similar results on 2D images of scapulae. ${ }^{25}$ We found the long lateral plate successfully addressed all fractures exiting at the subglenoid, middle and distal thirds of the lateral border.

The medial border of the scapula, compared to the lateral border, is much thinner and offers poor to no screw purchase..$^{10}$ The short medial plate performed marginally better than the long medial plate. Of all four plates, the medial plates measured the greatest plate offset and overhang. This might have been due to the angle between its superior and inferior limbs not being acute enough and causing the plate to extend off the medial border. The medial plate, as with the lateral plate, offers no variable angle screw placement option and no proximal or distal locking options for smaller diameter locking screws. ${ }^{26,27}$

The glenoid plate had the worst score for anatomical fit compared to the other three plates. It proved challenging to place the short triangular-shaped glenoid plate onto the spinoglenoid notch and posterior glenoid. The glenoid plate was not successful in addressing any glenoid fractures. These observations are in line with our previous findings. ${ }^{17}$ The Ideberg type 3, 4 and 6 fractures pose the greatest challenge to the treating surgeon and in our study, as we observed that the glenoid plate offered limited screw options to adequately fix these fractures. When the fracture propagated, inferior to the spine, towards the medial border, the glenoid plate was found to be inadequate to address the fracture. When addressing intra-articular glenoid fractures and the associated glenoid rim and/or neck fractures, we prefer cannulated screws as first-line of treatment for these fractures. A variety of fixation techniques, such as cannulated screws, buttressing plates, bone grafting (coracoid/iliac crest), cerclage wiring, suture anchors or a combination of these, have been described in the literature. ${ }^{28,29}$

The fixation of scapula fractures is not limited to the anatomical pre-contoured system. The use of alternative fixation is well described in the literature with good to excellent results. ${ }^{11,12,30}$ Non-anatomical plates, with or without K-wire/screw fixation and even plates designed to address a completely different fracture pattern at different anatomical sites, have been used to fix scapula fractures. Utilising different fixation techniques, as outlined in the literature, corroborates our observation that the current precontoured anatomical scapula plates might not be suitable to fit around all types of scapula fractures. Future developments should focus on introducing design changes to the existing designs to make them fit more fracture patterns.

The secondary aim of the study was to determine consensus on two available scapula fracture classifications. We used the AO/OTA and Ideberg classification systems to classify the different types of fractures - scapula body and neck fractures were classified using the AO/OTA classification system, and glenoid fractures were classified using the Ideberg classification system. We found that the consensus remains less than perfect. The AO/OTA and Ideberg classification systems are well described and often referred to in the literature. Although newer classification systems have been proposed, all the investigators unanimously decided on the AO/OTA and Ideberg classification systems.
In a previous study, Armitage et al. stated that many classification systems lack clinical correlation compared to actual fracture patterns. ${ }^{25}$ In another study, Bartoníček et al. reported that the available classifications are purely descriptive and have neither therapeutic nor prognostic implications. ${ }^{21}$ Recently, two new scapula fracture classifications systems were proposed which are yet to be adapted in our clinical facility, namely the more comprehensive AO/OTA classification, and the New International Classification for Scapula Fractures (NICSF). ${ }^{13,14}$

Neuhaus et al. compared the validity of the AO/OTA and the NICSF and concluded the NICSF system is validated and more reliable than the AO/OTA. ${ }^{15}$ Another study by Harvey et al. confirmed that the inter-rater reliability increased when CT images were used in scapula fracture classifications..$^{13}$ In both the classification systems, glenoid fractures were observed to have had the best agreement among the observers.

In our study, using 3D-printed fractured scapula models, we observed better consensus among the surgeons when describing glenoid fractures using the Ideberg classification compared to fracture classifications using the AO/OTA classification system.

Implementing 3D prototypes in practice has its limitations. The benefit of 3D printing is not limited to templating only as 3D-printed scapula prototypes have been used as an adjunct to radiographs in detailed preoperative planning and teaching. ${ }^{31-33}$ The authors caution readers that the cost and time spent on 3D prototyping process may not be feasible in all orthopaedic institutions. With the machinery and expertise needed, institutions embarking on such research need to consider the volume of complicated fracture patterns encountered in an orthopaedic practice, in order to justify the cost-benefit.

The primary limitation of this study was the small sample size of the fractured scapulae used in the study. The secondary limitation of the study was that only one anatomical plating system was used in the study as it is also the only commercially available plating system in South Africa. The ability to address the fracture with non-anatomical plates has been well documented. The study did not use plate bending or other methods to improve plate shape to improve fit and fixation that would be possible in the clinical setting. For future studies, the authors would recommend that other available plating systems, including those not necessarily designed for scapula fractures, and different fracture fixation techniques, be compared on a larger sample size of fractured scapula.

\section{Conclusion}

The long lateral plate had the best ability to fit scapula body fractures, followed by a combination of the long lateral plate and one of the medial plates, while the glenoid plate was found to be an unsatisfactory solution for addressing scapula body and glenoid fractures. Further emphasis on improving the scapula plate design is recommended. Classifying scapula fractures using existing scapula fracture classifications remains an underlying challenge among the shoulder surgeons in our part of the world.

\section{Ethics statement}

The authors declare that this submission is in accordance with the principles laid down by the Responsible Research Publication Position Statements as developed at the 2nd World Conference on Research Integrity in Singapore, 2010.

Prior to commencement of the study, ethical approval was obtained from the following ethical review board: University of Cape Town HREC Ref No: 311/2019.

All procedures were in accordance with the ethical standards of the responsible committee on human experimentation (institutional and national) and with the Helsinki Declaration of 1975 , as revised in 2008

Declaration

The authors declare authorship of this article and that they have followed sound scientific research practice. This research is original and does not transgress plagiarism policies. 


\section{Author contributions}

JJdW: Study conceptualisation, data collection, preparation of the first draft

RD: Data analysis, data representation, manuscript review and re-writing

BV: Study conceptualisation, manuscript review and re-writing

JPdP: Study conceptualisation, manuscript review and re-writing

CA: Study conceptualisation, manuscript review and re-writing

PAR: Study conceptualisation, manuscript review and re-writing

LCH: Data collection

HMY: Data collection

SS: Study conceptualisation, manuscript review and re-writing

SJLR: Study conceptualisation, manuscript review and re-writing

\section{ORCID}

De Wet JJ (D) https://orcid.org/0000-0001-5464-749X

Dey R (D) https://orcid.org/0000-0002-3616-1995

Du Plessis JP (iD) https://orcid.org/0000-0001-6469-7765

Anley C (D) https://orcid.org/0000-0002-5983-3520

Yimam HM (D) https://orcid.org/0000-0002-7929-2231

Sivarasu S (iD) https://orcid.org/0000-0002-0812-568X

Roche SJL (iD) https://orcid.org/0000-0002-5695-2751

\section{References}

1. Cole PA, Gauger EM, Schroder LK. Management of scapular fractures. J Am Acad Orthop Surg. 2012;20:130-41.

2. Bi AS, Kane LT, Butler BA, et al. Outcomes following extra-articular fractures of the scapula: A systematic review. Injury. 2020;51:602-10

3. Aldridge S, Gray M. Fractures of the scapula. Orthop Trauma. 2019;33:308-14.

4. Schroder LK, Gauger EM, Gilbertson JA, et al. Functional outcomes after operative management of extra-articular glenoid neck and scapular body fractures. J Bone Jt Surg 2016;98:1623-30

5. Tatro JM, Schroder LK, Molitor BA, et al. Injury mechanism, epidemiology, and Hospital trends of scapula fractures: A 10-year retrospective study of the National Trauma Data Bank. Injury. 2019;50:376-81.

6. Zlowodzki M, Bhandari M, Zelle BA, Kregor PJ, Cole PA. Treatment of scapula fractures: Systematic review of 520 fractures in 22 case series. J Orthop Trauma. 2006;20:230-33.

7. Chadwick EKJ, Van Noort A, Van Der Helm FCT. Biomechanical analysis of scapular neck malunion - A simulation study. Clin Biomech. 2004;19:906-12.

8. Hobbs H, Garrett B, Sanchez P, et al. Open reduction and internal fixation of scapula fractures. SA Orthop J. 2008;7:8-13.

9. Noguchi T, Mautner JF, Duncan SFM. Dorsal plate fixation of scapular fracture. J Hand Surg Am. 2017;42:843.e1-843.e5

10. Burke CS, Roberts CS, Nyland JA, et al. Scapular thickness-implications for fracture fixation. J Shoulder Elb Surg. 2006;15:645-48.

11. Panigrahi R, Madharia D, Das DS, et al. Outcome analysis of intra-articular scapula fracture fixation with distal radius plate: a multicenter prospective study. Arch Trauma Res. 2016;5:36406.

12. Hu $\mathrm{Y}$, Shi $\mathrm{H}$, Wang $\mathrm{F}$, et al. Functional outcomes of extra-articular scapula fracture fixation with distal humeral Y-type locking plate: A retrospective study. J Orthop Surg Res. 2019;14:176. https://doi.org/10.1186/s13018-019-1205-y.

13. Harvey E, Audigé $L$, Herscovici $D$, et al. Development and validation of the new international classification for scapula fractures. J Orthop Trauma. 2012;26:364-69.

14. Audigé L, Kellam JF, Lambert $\mathrm{S}$, et al. The $\mathrm{AO}$ foundation and orthopaedic trauma association (AO/OTA) scapula fracture classification system: Focus on body involvement. J Shoulder Elb Surg. 2014;23:189-96.

15. Neuhaus V, Bot AGJ, Guitton TG, et al. Scapula fractures: interobserver reliability of classification and treatment. J Orthop Trauma. 2014;28:124-29.

16. Acumed LLC. Scapula Plating System Brochure. Hillsboro. Available from: https://www. acumed.net/wp-content/uploads/2017/12/Scapula-Plating-System-Brochure.pdf. Accessed 14 August 2020.

17. Dey R, Sivarasu S, Charilaou J, et al. Evaluating the fit of current anatomical scapula reconstruction plates: a study using fifty scapulae. In: Proceedings of the 2020 Design of Medical Devices Conference. 2020 Design of Medical Devices Conference. Minneapolis, Minnesota, USA. April 6-9, 2020. V001T03A007. ASME. Minneapolis, Minnesota, USA American Society of Mechanical Engineers Digital Collection. Epub ahead of print 27 July 2020. https://doi.org/10.3109/17453679508995571.

18. Malhas AM, Skarparis YG, Sripada S, et al. How well do contoured superior midshaft clavicle plates fit the clavicle? A cadaveric study. J Shoulder Elb Surg. 2016;25:954-59.

19. Andermahr J, McKee M, Nam D. ORIF - Plate fixation for Glenoid fossa, extraarticular, simple. Available from: https://surgeryreference.aofoundation.org/orthopedic-trauma/ adult-trauma/scapula/glenoid-fossa-extraarticular-simple/orif-plate-fixation. Accessed 20 August 2020.

20. Ideberg R, Grevsten S, Larsson S. Epidemiology of scapular fractures Incidence and classification of 338 fractures. Acta Orthop Scand. 1995;66:395-97.
21. Bartoníček J, Tuček M, Klika D, et al. Pathoanatomy and computed tomography classification of glenoid fossa fractures based on ninety patients. Int Orthop. 2016;40:2383-92.

22. Koo TK, Li MY. A guideline of selecting and reporting intraclass correlation coefficients for reliability research. J Chiropr Med. 2016;15:155-63.

23. Nguyen TQD, Park AY, Distefano JG, et al. Congruency of scapula locking plates: Implications for implant design. ASME 2010 Summer Bioeng Conf SBC 2010. 2010;501-502.

24. Dugarte AJ, Tkany L, Schroder LK, et al. Comparison of 2 versus 3 dimensional fracture mapping strategies for 3 dimensional computerized tomography reconstructions of scapula neck and body fractures. J Orthop Res. 2017;36:265-71.

25. Armitage BM, Wijdicks CA, Tarkin IS, et al. Mapping of scapular fractures with three-dimensional computed tomography. J Bone Jt Surg - Ser A. 2009;91:2222-28.

26. Acumed LLC. Surgical Technique Locking Clavicle Plating System. Hillsboro. Available from: https://www.acumed.net/wp-content/uploads/2018/03/Acumed-Surgical-Technique-ENLocking-Clavicle-Plating-SHD10-05-B.pdf. Accessed 16 July 2019.

27. Acumed LLC. Acu-Loc $\circledast 2$ Wrist Plating System Product Overview. Hillsboro. Available from: https://www.acumed.net/wp-content/uploads/2016/01/Acumed-Brochure-EN-Acu-Loc-2HNW40-09-C.pdf. Accessed 14 August 2020.

28. Van Oostveen DPH, Temmerman OPP, Burger BJ, et al. Glenoid fractures: a review of pathology, classification, treatment and results. Acta Orthop Belg. 2014;80:88-98.

29. Theivendran K, McBryde CW, Massoud SN. Scapula fractures: A review. Trauma. 2008:10:25-33.

30. Cole PA, Gauger EM, Herrera DA, et al. Radiographic follow-up of 84 operatively treated scapula neck and body fractures. Injury. 2012;43:327-33.

31. Rengier F, Mehndiratta A, Von Tengg-Kobligk H, et al. 3D printing based on imaging data: Review of medical applications. Int J Comput Assist Radiol Surg. 2010;5:335-41.

32. Martelli $\mathrm{N}$, Serrano $\mathrm{C}$, Van den Brink $\mathrm{H}$, et al. Advantages and disadvantages of 3-dimensional printing in surgery: A systematic review. Surg. 2016;159:1485-500.

33. Bizzotto N, Sandri A, Regis D, et al. Three-dimensional printing of bone fractures: A new tangible realistic way for preoperative planning and education. Surg Innov. 2015;22:548-51. 